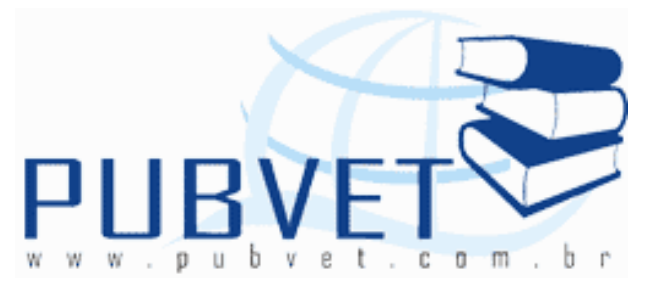

PUBVET, Publicações em Medicina Veterinária e Zootecnia.

\title{
Parâmetros biológicos das fases não-parasitárias de Rhipicephalus (Boophilus) microplus (Canestrini, 1887) (Acari: Ixodidae) infestados em bovinos sob condição controlada
}

Alexandre Thomé da Silva de Almeida ${ }^{1}$; Jociana Brugnerotto de Almeida ${ }^{1}$; Patrícia Suélen Barbosa Barros²; Luciana Carneiro Dimas²; Paula Grabner²

${ }^{1}$ Docentes da Faculdade São Lucas, Porto Velho - RO; alethomeprof@hotmail.com.

${ }^{2}$ Discentes de Medicina da Faculdade São Lucas, Porto Velho - RO.

\section{Resumo}

O trabalho de pesquisa e de controle de Rhipicephalus (Boophilus) microplus necessita de um grande número de informações tanto do meio abiótico como do meio biótico. Os bovinos possuem grande influência em sua população, e a utilização dos parâmetros biológicos de $R$. (B.) microplus torna-se primordial, principalmente aqueles relacionados à fase de vida livre deste ixodídeo. A pesquisa de referências foi realizada nas bases de dados: SciELO, MEDLINE, PUBMED, SCIENCE DIRECT, LILACS e CAPES - banco de teses. Os unitermos utilizados para a busca dos artigos foram: 1) Descritores - bovino, carrapato, oviposição em português e inglês; e 2) Nome científico da espécie Rhipicephalus (Boophilus) microplus e Boophilus microplus. No intuito de auxiliar as pesquisas com esse parasito de grande importância econômica, vimos compilar os valores mencionados pela literatura para os parâmetros 
ALMEIDA, A.T.S. et al. Parâmetros biológicos das fases não-parasitárias de Rhipicephalus (Boophilus) microplus (Canestrini, 1887) (Acari: Ixodidae) infestados em bovinos sob condição controlada. PUBVET, Londrina, V. 5, N. 39, Ed. 186, Art. 1251, 2011.

biológicos da fase não-parasitária de fêmeas de $R$.(B.) microplus e de sua prole.

Palavras-chave: Rhipicephalus (Boophilus) microplus, bovino, carrapato, oviposição.

\title{
Biological parameters of non-parasitic stages of Rhipicephalus (Boophilus) microplus (Canestrini, 1887) (Acari: Ixodidae) infested cattle in a controlled condition
}

\begin{abstract}
The research and the control of Rhipicephalus (Boophilus) microplus require a lot of information, concerning the abiotic elements as well as the biotic elements. One of the most important elements in the relationship between the host effect and the tick population is the bovine effect on the tick population. A search was performed in the following databases: SciELO, MEDLINE, PUBMED, SCIENCE DIRECT and LILACS. The keywords used for search for articles were: 1) Keywords - bovine, tick, oviposition in English and in Portuguese; and 2) Scientific name of specie - Rhipicephalus (Boophilus) microplus and Boophilus microplus. Thus, the utilization of biologic parameters of $R$. (B.) microplus is essential, fundamentally those related with the non-parasitic phase. To assist the work with this important parasite, we compiled the values cited in literature of the biologic parameters of the non parasitic phase of females of $R$. (B.) microplus, and its descendant.
\end{abstract}

Keywords: Rhipicephalus (Boophilus) microplus, bovine, tick, oviposition.

\section{INTRODUÇÃO}

Os parasitologistas há muito têm trabalhado para esclarecer a biologia do carrapato-do-boi, Rhipicephalus (Boophilus) microplus, e seus componentes ecológicos, além de verificar a influência das espécies e raças de bovinos sobre sua população. 
ALMEIDA, A.T.S. et al. Parâmetros biológicos das fases não-parasitárias de Rhipicephalus (Boophilus) microplus (Canestrini, 1887) (Acari: Ixodidae) infestados em bovinos sob condição controlada. PUBVET, Londrina, V. 5, N. 39, Ed. 186, Art. 1251, 2011.

Esse ectoparasito possui sua origem no sul da Ásia, onde foi encontrado parasitando artiodátilos nativos (HOOGSTRAAL, 1979). Com o comércio de gado zebuíno deste para outros continentes, este ixodídeo, atualmente, faz-se presente do paralelo $32^{\circ} \mathrm{N}$ ao correspondente no hemisfério sul, tendo-se ainda focos em $35^{\circ} \mathrm{N}$ e $35^{\circ} \mathrm{S}$ (LOMBARDO, 1975).

O território brasileiro, além de outros países, encontra-se, em grande parte, como área potencial ao desenvolvimento de $R$. (B.) microplus (HORN e ARTECHE, 1985), possuindo presença marcante na vida da pecuária nacional, e interferindo negativamente na produtividade do gado bovino (SARTOR et al., 1992) pela espoliação sangüínea, lesões cutâneas, transmissão de agentes patogênicos, entre outras ações deletérias (ARAGÃO, 1936; WHARTON et al., 1971; KAUFMAN, 1989; HONER e GOMES, 1990).

As práticas isoladas para o controle do carrapato têm sofrido questionamentos, visto que o controle químico como única forma de controle já se provou ineficaz (HONER e GOMES, 1990; VALLE, 2000). Somando-se a isto, o conceito de erradicação foi suprimido pela "flexibilidade genética dos organismos". E o melhor caminho está em promover uma diminuição desses efeitos econômicos negativos causados pelo R. (B.) microplus pelo uso da genética dos bovinos (HONER e GOMES, 1990).

Dentre as diversas alternativas de abordagem do problema, a grande tendência da pesquisa científica contemporânea para o controle do $R$. (B.) microplus centra-se na busca da resistência natural ao $R$. (B.) microplus, para se estabelecer indicadores, raças de bovinos e estudos de verificação de indivíduos resistentes. Nesse sentido uma forma de avaliação da interferência do hospedeiro na biologia do carrapato, é verificar os parâmetros biológicos do ixodídeo, na fase parasitária e na fase de vida livre.

Dessa forma, utilizando-se os parâmetros biológicos do ixodídeo, esperase responder às questões: de que forma e em qual nível a resistência do hospedeiro interfere na biologia do carrapato? 
ALMEIDA, A.T.S. et al. Parâmetros biológicos das fases não-parasitárias de Rhipicephalus (Boophilus) microplus (Canestrini, 1887) (Acari: Ixodidae) infestados em bovinos sob condição controlada. PUBVET, Londrina, V. 5, N. 39, Ed. 186, Art. 1251, 2011.

Para tanto, é importante que a literatura nos forneça elementos para avaliação e interpretação dos valores dos parâmetros biológicos relacionados à vida não-parasitária das fêmeas e de sua prole (ovos, larvas e ninfas).

\section{METODOLOGIA}

Os artigos científicos e as teses encontradas para a realização deste artigo de revisão foram encontrados nos bancos de dados on line citados a seguir: SciELO (Scientific Electronic Library Online); MEDLINE (EUA National Library of Medicine); PUBMED (National Library of Medicine); CAPES (Coordenação de Aperfeiçoamento de Pessoal de Nível superior) - Banco de Teses; Science Direct e LILACS (Literatura Latinoamericana em Ciências da Saúde).

Os termos utilizados foram selecionados segundo os Descritores em Ciências da Saúde - DeCS da Biblioteca Virtual em Saúde - BVS, que seguem: bovino, carrapato, oviposição em português e inglês. E o nome científico válido para a espécie - Rhipicephalus (Boophilus) microplus e sua sinonímia Boophilus microplus (MURRELL e BARKER, 2003).

Todos os trabalhos acadêmicos e científicos escolhidos apresentaram dados dos parâmetros biológicos da fase não parasitária (fase de vida livre) de $R$. (B.) microplus, das fêmeas e/ou de sua prole, em condição de interação parasitária apenas com hospedeiros bovinos (raças de Bos taurus e B. indicus), sem qualquer interferência de drogas ou outras substâncias que viessem a interferir em seu ciclo biológico. E como critério de inclusão/ exclusão analisouse os dados presentes no resumo e os dados apresentados nos resultados, alcançando-se o número de 36 estudos.

O período de abrangência pesquisado foi aquele disponibilizado pelo próprio banco de dados. 


\section{PARÂMETROS BIOLÓGICOS RELACIONADOS ÀS FÊMEAS}

\section{Peso médio das fêmeas ingurgitadas}

Os valores encontrados na literatura para peso médio das fêmeas ingurgitadas (ou teleóginas) são decorrentes, na sua maioria, de trabalhos relacionados aos mais diversos objetivos. Agora, este parâmetro biológico possui importância na verificação de outros, como peso da postura, índices de eficiência reprodutiva e nutricional, tanto de uma maneira direta, quanto indireta.

Neste aspecto, a literatura traz valores pouco uniformes, antes mesmo da década de 70, Nagar (1968) sugeriu que fêmeas mais leves precisem de menos tempo para completar a oviposição. Já em 1970 Wharton e Utech verificaram que $88 \%$ dos pesos médios das fêmeas foram superiores a 150 miligramas, com intervalo entre 40 e 305 miligramas. Wagland (1975) observou o peso médio das fêmeas como sendo de 174 miligramas para a raça zebuína e 205 miligramas para a raça européia mantida a $29 \pm 1^{\circ} \mathrm{C}$ e $95 \%$ de umidade relativa (UR) durante a $4^{a}$ infestação. Oliveira (1979) encontrou uma variação entre 237,2 e 310,6 miligramas num intervalo de 105,6 a 440,0 miligramas, em temperatura ambiente.

Dentre os trabalhos publicados na década de 80, Davey et al. (1980) verificaram um alto peso médio de fêmeas, que foi de 448 miligramas, a $27 \pm$ $1{ }^{\circ} \mathrm{C}, 80 \pm 10 \%$ UR e 12 horas de fotofase. Costa (1982) verificou um valor médio de 223,30 miligramas, em um intervalo de 120 a 370 miligramas, em condições de laboratório a $27^{\circ} \mathrm{C}, 80$ a $95 \%$ UR em uma ausência quase completa de luz. Maradey (1983) constatou um valor médio para a massa de teleóginas de 0,33 $\pm 0,04$ gramas, sob $27^{\circ} \mathrm{C}$ e UR superior a $70 \%$. Vasconcelos et al. (1986) referiram-se a 261,13 $\pm 16,33$ miligramas, para taurinos, e 244,24 $\pm 11,64$ miligramas, para zebuínos. 
Na década de 1990, Bittencourt (1990) observou o peso médio das fêmeas com 276,7 miligramas, sob condições de laboratório a $27 \pm 2^{\circ} \mathrm{C}$ e 80 $\pm 10 \%$ UR, já Furlong (1990) verificou o peso inicial das teleóginas, com valor médio de 243,33 miligramas, em BOD regulada a $27^{\circ} \mathrm{C}$ e UR superior a $80 \%$. Azevedo (1996) realizou infestações leves e pesadas, verificando os valores de, respectivamente, $274,06 \pm 79,09$ miligramas e 281,34 $\pm 71,38$ miligramas, a $28^{\circ} \mathrm{C}$ e UR em torno de $80 \%$. Considerou que este parâmetro biológico é confiável para se avaliar a resistência adquirida, quando se tratar, principalmente, de infestações leves em bovinos.

No inicio do século XXI, Chagas, Furlong e Nascimento (2001) observaram as teleóginas no ambiente e concluíram que o deslocamento é devido à luminosidade, cobertura vegetal e temperatura, havendo maior participação desta em seu deslocamento. Almeida (2002) trabalhou com as raças Angus, Canchim, Caracu e Charolês sob condições controladas de $27 \pm$ $1^{\circ} \mathrm{C}, 80 \pm 10 \%$ UR e escotofase, encontrando 309,00 $\pm 48,75$ miligramas, $267,60 \pm 51,33$ miligramas, $209,40 \pm 51,41$ miligramas e $297,00 \pm 39,50$ miligramas, respectivamente. Santos e Furlong (2002) trabalharam com infestações em bovinos 15/16 holandês $x$ zebu, e dividiram as observações em grupos por peso das teleóginas, sendo grupo das pequenas (até $0,199 \mathrm{~g}$ ), das médias $(0,200$ a 0,299g) e grandes (acima de 0,299), tendo-se respectivamente $0,158 \pm 0,028 \mathrm{~g}, 0,241 \pm 0,026$ e 0,331 $\pm 0,028$. Louzada e Daemon (2003) trabalharam com bovinos de leite e com efeito da imersão em água destilada, para o grupo controle $(n=15)$ aferiram 170,18 $\pm 29,29$ miligramas. Carvalho et al. (2010) observaram em seu grupo controle as teleóginas com peso médio de 0,2044 $\pm 0,0064 \mathrm{~g}$, não indicando a raça de infestação.

\section{Período de pré-postura}

Para o período de pré-postura, Rohr (1909) realizou estudo em temperatura ambiente durante dois a seis dias entre as temperaturas de 
ALMEIDA, A.T.S. et al. Parâmetros biológicos das fases não-parasitárias de Rhipicephalus (Boophilus) microplus (Canestrini, 1887) (Acari: Ixodidae) infestados em bovinos sob condição controlada. PUBVET, Londrina, V. 5, N. 39, Ed. 186, Art. 1251, 2011.

$19,9^{\circ} \mathrm{C}$ a $23,4^{\circ} \mathrm{C}$. De acordo com Nagar (1968) o período de pré-postura, em geral, é um período mais curto e é fixado para cada espécie, com pequenas variações intraespecíficas. Este período significa um período latente ou um tempo inicial requerido para conversão dos nutrientes adquiridos pelo carrapato até que surja o primeiro ovo, sendo, então, uma taxa metabólica independente da quantidade de nutrientes ingeridos. Não podendo afirmar que o período de pré-postura depende do peso da fêmea.

Alvarado e Gonzalez (1979) referiram-se a $86 \%$ de sua amostragem com um período de pré-postura de três dias, a $26^{\circ} \mathrm{C}$ e UR superior a $80 \%$. Davey et al. (1980) verificaram para o grupo perturbado uma média de três dias e para o grupo não-perturbado 3,2 dias, sem diferença estatística significativa entre os grupos. Costa (1982) relatou um período médio de 4,14 dias, em um intervalo de quatro a cinco dias. Maradey (1983), utilizando unidades experimentais de 2,5 gramas de teleóginas, observou 1,81 $\pm 0,71$ dias, tendo o $2^{\circ}$ dia como modal. Khan (1986), em seu trabalho na Índia, averiguou 3,4 dias em média, sob $26 \pm 4^{\circ} \mathrm{C}$ e $80 \pm 10 \%$ UR. Short et al. (1989) em condições controladas do experimento, a $25^{\circ} \mathrm{C}$ e $85 \%$ de UR, obtiveram para este período uma mediana de 3,2 dias, num intervalo de três a quatro dias. Bittencourt (1990) observou um valor médio para o período de 2,2 dias. No mesmo ano Furlong verificou 3,27 dias. Gloria et al. (1993) relataram um valor médio de 2,73 dias, para a temperatura de $27 \pm 1^{\circ} \mathrm{C}$ e 80 $\pm 10 \%$ UR. Azevedo (1996) verificou na infestação pesada 3,07 $\pm 0,96$ dias, na infestação leve 3,02 $\pm 0,92$ dias, e houve uma tendência de redução do período de pré-postura nos bovinos que já possuíam contato prévio com o carrapato.

O intervalo de variação encontrado na literatura, para estudos com temperaturas em torno de $27^{\circ} \mathrm{C}$, mostra-se com certa uniformidade, sendo referido variando de dois a quatro dias (HITCHCOCK, 1955; DAVEY et al. 1980; GLORIA et al., 1993). Agora Khan (1986) observou um intervalo de dois a cinco dias, enquanto Alvarado e Gonzales (1979) relataram uma variação de dois a seis dias no período de pré-postura. 
Short et al. (1989) descreveram uma exceção para o fato de terem observado que os parâmetros biológicos, de uma maneira geral, possuem períodos mais curtos em condições de temperatura e umidade relativa favoráveis, e o comportamento inverso em condições desfavoráveis. A exceção verificada, então, foi no período de pré-postura, com um comportamento mais longo nas duas condições.

Segundo Chagas, Furlong e Nascimento (2001) no inverno houve um período de 9,8 dias e no verão de cinco dias. Almeida (2002) trabalhou com as raças Angus, Canchim, Caracu e Charolês sob condições controladas, encontrando 2,82 $\pm 0,39$ dias, 2,98 $\pm 0,14$ dias, 2,98 $\pm 0,14$ dias e 3,08 \pm 0,34 , respectivamente. Santos e Furlong (2002) verificaram para o grupo das teleóginas pequenas $3,63 \pm 0,845$ dias, grupo das teleóginas médias 3,80 \pm 0,666 dias e grupo das teleóginas grandes 3,74 $\pm 0,570$ dias. Louzada e Daemon (2003) trabalharam com bovinos de leite e com efeito da imersão em água destilada, para o grupo controle $(n=15)$ aferiram $2,33 \pm 0,48$ dias. Silva et al. (2007) trabalharam com um pool de teleóginas coletadas na região de estudo, onde seu grupo controle foi mantido sob $32^{\circ} \mathrm{C}$ e $65 \%$ UR, encontrando $12 \pm 0,0$ dias.

\section{Período de postura}

O período de postura verificado no estudo realizado por Rohr (1909) foi de 12 a 21 dias, em temperatura ambiente, variando de $21,1^{\circ} \mathrm{C}$ a $23^{\circ} \mathrm{C}$. Hitchcock (1955) observou um intervalo de 13 a 16 dias em seu estudo, a uma temperatura de $26,7^{\circ} \mathrm{C}$ e $80 \%$ de UR, e um período de 11 a 14 dias com a mesma temperatura e $90 \%$ de UR. Nagar (1968) comentou que o período de postura é longo e varia entre espécimes, além de indicar a taxa e a duração da conversão necessária para ocorrer a postura. Somando-se a isto, Kaufman (1989) relatou que os mecanismos que levam à falha de postura não são conhecidos nos carrapatos. Bennett (1974a), estudando a influência do tamanho da fêmea na produção de ovos, verificou que o pico de postura 
ALMEIDA, A.T.S. et al. Parâmetros biológicos das fases não-parasitárias de Rhipicephalus (Boophilus) microplus (Canestrini, 1887) (Acari: Ixodidae) infestados em bovinos sob condição controlada. PUBVET, Londrina, V. 5, N. 39, Ed. 186, Art. 1251, 2011.

ocorreu entre $04^{\circ}$ e $5^{\circ}$ dias e que a curva de porcentagem acumulada mostrou que $50 \%$ dos ovos foram postos até o $5^{\circ}$ dia e $95 \%$ em torno do $10^{\circ}$ dia, sendo completada próxima do $16^{\circ}$ dia após o início da postura. Alvarado e Gonzales (1979) observaram que $91 \%$ dos ovos foram postos até o $10^{\circ}$ dia.

Davey et al.(1980) verificaram um período de postura médio de 17,2 dias e observaram o pico de postura no $3^{\circ} \mathrm{dia}$; onde a maior produção ocorreu do $2^{\circ}$ ao $6^{\circ}$ dia de postura; após este último dia houve forte declínio na quantidade de ovos postos. Costa (1982) descreveu 7,36 dias como valor médio, num intervalo de cinco a nove dias. Khan (1986) verificou um intervalo de 10 a 13 dias, com um valor médio de 11,5 dias.

Bittencourt (1990) relatou esse período com 11,5 dias, de valor médio. Furlong, também em 1990, descreveu o período de postura médio com 10,04 dias. Gloria et al. (1993) observaram um período de postura de três a 16 dias, com 11,06 dias de média. O pique diário médio de 657,80 ovos ocorreu no primeiro dia após o início do período de postura, e $06^{\circ}$ dia foi aquele que marcou a queda do ritmo de postura, com cerca de $90 \%$ da postura média total colocada. Azevedo (1996) verificou, na parcela estudada, um período de $17,44 \pm 3,87$ dias e, na infestação leve, um valor de 13,07 $\pm 2,69$ dias, com uma tendência de aumento desse período na infestação pesada e o inverso na infestação leve.

Já Almeida (2002) trabalhando sob condições controladas verificou $14,04 \pm 2,52$ dias para Angus, 13,04 \pm 2,04 dias para Canchim, 12,16 \pm 1,92 dias para Caracu e 15,54 \pm 2,69 para Charolês. Santos e Furlong (2002) verificaram para o grupo das teleóginas pequenas $11,4 \pm 1,820$ dias, grupo das teleóginas médias 12,1 $\pm 2,151$ dias e grupo das teleóginas grandes $12,6 \pm 2,160$ dias. Louzada e Daemon (2003) aferiram para o grupo controle 11,26 $\pm 2,86$ dias. Enquanto Silva et al. (2007) verificaram $25 \pm$ 0,00 dias. E Pereira (2008) para observar o período de postura dessas fêmeas, manteve-as de $21,1 \mathrm{C}$ a $23^{\circ} \mathrm{C}$, sendo observado de 2 a 21 dias. 
ALMEIDA, A.T.S. et al. Parâmetros biológicos das fases não-parasitárias de Rhipicephalus (Boophilus) microplus (Canestrini, 1887) (Acari: Ixodidae) infestados em bovinos sob condição controlada. PUBVET, Londrina, V. 5, N. 39, Ed. 186, Art. 1251, 2011.

\section{Peso médio da massa de ovos}

O peso médio da massa de ovos encontrado por Rohr (1909) a uma temperatura ambiente média de $22^{\circ} \mathrm{C}$ foi de 123,55 miligramas, com intervalo de 76,45 a 201,60 miligramas, demonstrando que o número médio de ovos postos foi de 2.471 ovos. Para Sutherst et al. (1978), há uma equivalência de 123,55 miligramas para um intervalo de 1.529 - 3.046 ovos. Hitchcock (1955) verificou que o número de ovos postos a $26,7^{\circ} \mathrm{C}$ e $80 \%$ UR foram 2.592 ovos que, transformado, segundo Sutherst et al. (1978), indicou 129,9 miligramas de postura. Wagland (1975), na $4^{a}$ infestação, verificou para o peso médio dos ovos 100 miligramas quando infestados em zebuínos e 114 miligramas quando infestados em gado europeu.

Alvarado e Gonzales (1979) relataram uma quantidade média de ovos postos por teleógina igual a 3.285 que, transformada, segundo Sutherst et al. (1978), indica 164,25 miligramas de postura. Davey et al. (1980) referiram-se a uma média de 449,0 miligramas e intervalo de 257 a 621 miligramas para o grupo perturbado diariamente, e 447,0 miligramas de média e intervalo de 301 a 647 miligramas de intervalo para o grupo não-perturbado. Costa (1982) verificou um peso médio de 100,40 miligramas, com intervalo de 44 a 169 miligramas. Maradey (1983) em seu estudo, com unidades experimentais, observou para a massa total de ovos o valor médio de 0,95 $\pm 0,26$ gramas que, transformado, indica o valor de 124,51 miligramas de ovos por fêmea da unidade experimental.

Khan (1986) averiguou $1.612,3$ ovos postos em média que, transformados, segundo Sutherst et al. (1978), indicam 80,62 miligramas de postura, em um intervalo de 1.031 a 2.346 ovos. Vasconcelos et al. (1986) verificaram que o peso da massa de ovos foi de 84,0 miligramas para o grupo dos taurinos e 82,7 miligramas para o grupo dos zebuínos, indicando que este parâmetro possui menor sensibilidade do que o número de teleóginas desprendidas para comparar resistência entre hospedeiros. Bittencourt (1990) observou o número médio de ovos postos igual a $3.051,3$ ovos que, 
ALMEIDA, A.T.S. et al. Parâmetros biológicos das fases não-parasitárias de Rhipicephalus (Boophilus) microplus (Canestrini, 1887) (Acari: Ixodidae) infestados em bovinos sob condição controlada. PUBVET, Londrina, V. 5, N. 39, Ed. 186, Art. 1251, 2011.

transformado, segundo Sutherst et al. (1978), indica 163,7 miligramas de postura. Ainda neste ano, Furlong (1990) constatou a massa de ovos com valor médio de 111,52 miligramas.

Gloria et al. (1993) verificaram a média de 140,08 miligramas de postura, a $27^{\circ} \mathrm{C}$ e umidade relativa de $80 \pm 10 \%$. Azevedo (1996), trabalhando com infestações pesadas e leves, verificaram, respectivamente, $127,57 \pm 43,45$ miligramas e 108,98 $\pm 45,49$ miligramas, indicando, ainda, uma tendência de redução do peso da massa de ovos nas infestações leves.

Chagas, Furlong e Nascimento (2001) observaram os valores médios no inverno de $0,12 \mathrm{~g}$ e no verão de $0,11 \mathrm{~g}$. Almeida (2002) trabalhou com as raças Angus, Canchim, Caracu e Charolês sob condições controladas, encontrando $172,09 \pm 35,36$ miligramas, $157,95 \pm 38,71$ miligramas, $117,61 \pm 34,58$ miligramas e 174,03 $\pm 30,61$ miligramas, respectivamente. Santos e Furlong (2002) verificaram para o grupo das teleóginas pequenas $0,072 \pm 0,023 \mathrm{~g}$, grupo das teleóginas médias $0,116 \pm 0,032 \mathrm{~g}$ e grupo das teleóginas grandes $0,169 \pm 0,031 \mathrm{~g}$. Louzada e Daemon (2003) aferiram para o grupo controle $91,35 \pm 21,61$ miligramas. Carvalho et al. (2010) verificou uma média de $0,1061 \pm 0,0036 \mathrm{~g}$.

Segundo Nagar (1968), a quantidade de nutrientes ingeridos pelo carrapato é utilizada, obviamente, para produção de ovos. E inferiu que, o nível em que isto ocorre depende da taxa metabólica que, teoricamente, pode variar entre espécies e entre indivíduos de carrapatos.

\section{Índice de eficiência reprodutiva (IER) e nutricional (IEN)}

Bennett (1974a) formulou expressões matemáticas para verificação da eficiência reprodutiva e nutricional das fêmeas, como seguem: 1) Índice de eficiência reprodutiva: peso da massa de ovos dividido pelo peso inicial da fêmea ingurgitada, multiplicado por cem, e 2) Índice de eficiência nutricional: peso da massa de ovos dividido pela diferença entre o peso inicial da fêmea ingurgitada e o peso final da fêmea (após o término da postura), multiplicado 
ALMEIDA, A.T.S. et al. Parâmetros biológicos das fases não-parasitárias de Rhipicephalus (Boophilus) microplus (Canestrini, 1887) (Acari: Ixodidae) infestados em bovinos sob condição controlada. PUBVET, Londrina, V. 5, N. 39, Ed. 186, Art. 1251, 2011.

por cem. Baseando-se nestas expressões averiguou que, para o grupo com peso médio inicial de 182 miligramas o IER e IEN foram, respectivamente, de $54,2 \%$ e $83,8 \%$, e para o grupo com peso médio inicial de 225 miligramas o IER e IEN foram, respectivamente, de $62,0 \%$ e $86,0 \%$, sendo estes os melhores valores encontrados entre os grupos trabalhados, a uma temperatura de $29,4^{\circ} \mathrm{C}$.

Bennett (1974b) verificou o IER e o IEN sob a temperatura constante de $26,6^{\circ} \mathrm{C}$, encontrando os valores de $58,0 \%$ e $77,1 \%$, respectivamente. A melhor eficiência de produção de ovos foi observada a $29,4^{\circ} \mathrm{C}$, pelo fato de terem resultado os maiores índices, tanto do IER quanto do IEN. Relatou, ainda, que a luminosidade possui significante efeito sobre a oviposição de $R$. (B.) microplus, fazendo com que seu IER e IEN fossem menores sob luminosidade do que quando mantidas em escotofase. Wagland (1975) não observou diferença no índice reprodutivo entre as raças utilizadas, tendo-se 0,57 para a raça zebuíana e 0,58 para a raça européia.

Davey et al. (1980) referiram-se ao índice de eficiência de conversão (IEC), onde os resultados apresentados foram: para o grupo perturbado a média de 0,565 e um intervalo de 0,421 a 0,652 e, para o grupo nãoperturbado, uma média de 0,594, com intervalo de 0,281 a 0,663. O CEI foi significativamente baixo para o grupo de fêmeas manipulado. Costa (1982) verificou um valor médio de 0,458 para o IEC, com um intervalo de 0,164 a 0,607 . Maradey (1983) averiguou o índice de produção de ovos com 37,81 \pm $10,24 \%$ e o índice nutricional com $55,61 \pm 12,73 \%$.

Bittencourt (1990) em seu experimento observou o IER com valor médio igual a 59,6\%. Furlong, ainda em 1990 , encontrou um valor de $45,99 \%$ para o IER e $64,38 \%$ para o IEN. Gloria et al. (1993) relataram um IER com valor médio de $58,07 \%$ e intervalo de 43,93 a $64,97 \%$, e para o IEN $78,60 \%$ de média e 65,61 a 83,60\% de intervalo. Azevedo (1996), em seu estudo com infestações leves e pesadas, constatou um IER para infestações pesadas de $42,36 \pm 9,32 \%$ e de $38,82 \pm 12,04 \%$ para infestações leves. Concluiu, ainda, 
ALMEIDA, A.T.S. et al. Parâmetros biológicos das fases não-parasitárias de Rhipicephalus (Boophilus) microplus (Canestrini, 1887) (Acari: Ixodidae) infestados em bovinos sob condição controlada. PUBVET, Londrina, V. 5, N. 39, Ed. 186, Art. 1251, 2011.

que este parâmetro biológico não é adequado para se avaliar a resistência adquirida por bovinos ao carrapato.

Chagas, Furlong e Nascimento (2001) encontraram IOP no inverno de $46 \%$ e no verão de $47 \%$, e IN no inverno $67 \%$ e no verão de $62 \%$. Almeida (2002) trabalhou com as raças Angus, Canchim, Caracu e Charolês sob condições controladas, encontrando IER 55,93 $\pm 9,17 \%$ e IEN 76,87 $\pm 8,45 \%$, IER $58,69 \pm 9,45 \%$ e IEN $77,93 \pm 8,78 \%$, IER $55,93 \pm 7,91 \%$ e IEN $74,89 \pm$ $7,20 \%$ e IER $58,76 \pm 7,16 \%$ e IEN $77,81 \pm 8,47 \%$, respectivamente. Santos e Furlong (2002) calcularam IER e IEN para o grupo das teleóginas pequenas $45,7 \pm 11,29 \%$ e $63,3 \pm 12,40 \%$, grupo das teleóginas médias $47,8 \pm 11,83 \%$ e $66,9 \pm 10,83 \%$ e grupo das teleóginas grandes $51,1 \pm 8,73 \%$ e $70,2 \pm$ $7,56 \%$. Louzada e Daemon (2003) aferiram para o grupo controle um IER de $53,44 \pm 7,19 \%$ e IEN $82,82 \pm 4,54 \%$. Carvalho et al. (2010) observaram que o Índice de Oviposição foi de $51,9133 \pm 0,5181 \%$ e Índice Nutricional $74,0122 \pm 0,5554 \%$.

\section{PARÂMETROS BIOLÓGICOS RELACIONADOS À PROLE}

\section{Período de incubação dos ovos}

Rohr (1909) estudou o período de incubação dos ovos em temperaturas que variaram de zero a $35^{\circ} \mathrm{C}$, tanto em temperatura fixa, em câmara, quanto na ambiente. Em temperatura média ambiente de $21^{\circ} \mathrm{C}$ observou uma variação de 43 a 63 dias, e na temperatura fixa de $30^{\circ} \mathrm{C}$, de 17 a 23 dias. Hitchcock (1955) relatou que não houve constatação desse período, quando os ovos foram colocados em uma faixa de umidade relativa (UR) inferior a $70 \%$, sendo necessárias então, altas umidades relativas e temperaturas para que se obtivesse uma alta porcentagem de eclosão. O menor período de incubação dos ovos, a temperatura constante de $25,6^{\circ} \mathrm{C}$ e UR, variando entre 50 e $90 \%$, foi de 25 dias. Bennett (1974a) verificou um período de incubação médio de 29 dias sob condições de laboratório. Alvarado e Gonzales (1979) encontraram 
ALMEIDA, A.T.S. et al. Parâmetros biológicos das fases não-parasitárias de Rhipicephalus (Boophilus) microplus (Canestrini, 1887) (Acari: Ixodidae) infestados em bovinos sob condição controlada. PUBVET, Londrina, V. 5, N. 39, Ed. 186, Art. 1251, 2011.

$77 \%$ de sua amostra variando entre 22 e 24 dias, sendo a moda igual a 22 dias, sob condições controladas.

Davey et al. (1980) estudaram a biologia de ovipostura sob condições controladas, com 12 horas de fotofase, e encontraram um período de incubação médio de 23,3 dias, independentemente da perturbação, com intervalo entre 22 e 26 dias. Costa (1982) relatou um intervalo de variação de 23 a 27 dias, com um período médio de incubação de 24,90 dias.

Bittencourt (1990) verificou, em seu trabalho, um período de 25,3 dias. Furlong (1990) observou um período de incubação dos ovos com média igual a 25,36 dias. Short et al. (1989), na etapa controlada do experimento, verificaram esse período com mediana de 32 dias, e intervalo de 29 a 34 dias. O período de incubação referido por Gloria et al. (1993) possuiu uma média igual a 25,28 dias e um intervalo de variação entre 24 e 27 dias. Azevedo (1996), trabalhando com diferentes níveis de infestação, observou que na infestação pesada o período de incubação foi de 34,77 \pm 8,02 dias e, na infestação leve, foi de $31,25 \pm 4,00$ dias. Este autor, ainda cita que foi a infestação pesada que permitiu o prolongamento do período relacionado a este parâmetro; o período de incubação não apresentou correlação com qualquer outro parâmetro biológico, porém demonstrou ser útil para avaliar a resistência adquirida pelos bovinos ao $R$. (B.) microplus.

Almeida (2002), sob condições controladas, aferiu 25,54 $\pm 0,90$ dias para Angus, 24,94 \pm 0,84 dias para Canchim, 25,94 $\pm 0,97$ dias para Caracu e 24,71 \pm 0,76 dias para Charolês. Enquanto Louzada e Daemon (2003) aferiram para o grupo controle um PIO de $24,53 \pm 0,83$ dias.

\section{Período de eclosão das larvas}

Com relação ao período de eclosão das larvas, Alvarado e Gonzales (1979) relataram que, sob condições de laboratório, $89 \%$ da amostra tiveram o período de eclosão larval com variação de cinco a sete dias. Bittencourt (1990) verificou esse período como tendo 7,1 dias, em média. 
ALMEIDA, A.T.S. et al. Parâmetros biológicos das fases não-parasitárias de Rhipicephalus (Boophilus) microplus (Canestrini, 1887) (Acari: Ixodidae) infestados em bovinos sob condição controlada. PUBVET, Londrina, V. 5, N. 39, Ed. 186, Art. 1251, 2011.

Almeida (2002) trabalhou com as raças Angus, Canchim, Caracu e Charolês sob condições controladas, encontrando 8,69 $\pm 2,57$ dias, 6,70 \pm 1,56 dias, 6,10 $\pm 1,52$ dias e 9,35 $\pm 2,48$ dias, respectivamente. Louzada e Daemon (2003) aferiram para o grupo controle um PIO de 7,8 $\pm 3,82$ dias.

\section{Porcentagem de eclosão larval}

Hitchcock (1955) verificou em seu estudo que para a porcentagem de eclosão obter valores elevados, houve a necessidade de se associarem altas temperaturas e umidades relativas. Bennett (1974b) relatou que a temperatura de $29,4^{\circ} \mathrm{C}$ foi a melhor daquelas experimentadas, visto ter aí apresentado, além de outras características, uma porcentagem de eclosão larval de 75 a $80 \%$. Costa (1982) verificou uma média de $80,90 \%$, em sua estimativa de eclosão, em um intervalo de 25 a 100\%. Short et al. (1989) observaram uma média de $64,83 \%$ de eclosão larval, sob $25^{\circ} \mathrm{C}$ e $85 \%$ UR. Bittencourt (1990) em sua avaliação observou uma porcentagem de eclosão média igual a 92,3\%. Gloria et al. (1993) encontraram porcentagens de eclosão entre zero e $100 \%$, com valor médio de $98,33 \%$, sendo que deste intervalo, apenas uma fêmea de toda a amostra produziu ovos inférteis, com fêmeas restantes obtendo $100 \%$ de eclosão larval.

Almeida (2002) trabalhou sob condições controladas, encontrando $83,76 \pm 21,60 \%$ para Angus, 87,68 $\pm 24,51 \%$ para Canchim, 84,12 $\pm 23,83 \%$ para Caracu e $88,2 \pm 18,88 \%$ para Charolês. Louzada e Daemon (2003) aferiram para o grupo controle $74,00 \pm 31,35 \%$. Carvalho et al. (2010) observaram 94,3 $\pm 1,350 \%$.

Além dessas porcentagens citadas, Kaufman (1989) relatou que os mecanismos de não-eclosão larval não são conhecidos nos carrapatos. 
ALMEIDA, A.T.S. et al. Parâmetros biológicos das fases não-parasitárias de Rhipicephalus (Boophilus) microplus (Canestrini, 1887) (Acari: Ixodidae) infestados em bovinos sob condição controlada. PUBVET, Londrina, V. 5, N. 39, Ed. 186, Art. 1251, 2011.

\section{Período de sobrevivência larval}

Em seu estudo, Hitchcock (1955) observou que o período de sobrevivência larval a $29,4{ }^{\circ} \mathrm{C}$ foi de $17,25,47$ e 80 dias para as umidades relativas de 80, 85, 90 e $95 \%$, respectivamente. Khan (1986) verificou para esse parâmetro o intervalo de 17 a 41 dias, sob $26 \pm 4^{\circ} \mathrm{C}$ e $80 \pm 10 \%$ UR. Costa (1982) verificou um intervalo entre 65 e 122 dias de sobrevivência larval.

Almeida (2002) trabalhou com as raças Angus, Canchim, Caracu e Charolês sob condições controladas, encontrando 90,77 \pm 5,56 dias, 104,12 $\pm 5,59$ dias, $100,12 \pm 9,86$ dias e 94,65 \pm 5,40 dias, respectivamente. Louzada e Daemon (2003) aferiram para o grupo controle 75,53 $\pm 18,71$ dias.

\section{Período de mortalidade larval}

Almeida (2002) trabalhou com as raças Angus, Canchim, Caracu e Charolês sob condições controladas, encontrando $61,71 \pm 5,50$ dias, 57,59 \pm 11,68 dias, 58,06 $\pm 11,00$ dias e 66,35 $\pm 5,27$ dias, respectivamente.

$\mathrm{Na}$ revisão de literatura realizada não se verificou outro valor referenciado para o período de mortalidade larval.

\section{Correlações entre parâmetros biológicos da fase não-parasitária de $\boldsymbol{R}$.}

\section{(B.) microplus}

Alguns trabalhos verificaram a relação ou correlação entre o peso de cada uma das fêmeas e da massa de ovos produzida por elas, onde Bennett (1974a) confirmou que há uma relação direta entre o peso inicial da fêmea e a quantidade de ovos postos por ela, e que aquelas consideradas leves (peso igual ou inferior a 100 miligramas), produziam poucos ovos e tinham um período de postura pequeno, por causa de sua baixa eficiência em converter o 
ALMEIDA, A.T.S. et al. Parâmetros biológicos das fases não-parasitárias de Rhipicephalus (Boophilus) microplus (Canestrini, 1887) (Acari: Ixodidae) infestados em bovinos sob condição controlada. PUBVET, Londrina, V. 5, N. 39, Ed. 186, Art. 1251, 2011.

alimento em ovos. Neste sentido, fêmeas com peso entre 100 e 370 miligramas possuíam eficiência mais uniforme de conversão alimentar.

Os trabalhos analisados indicam que há uma correlação direta entre os parâmetros supracitados, como o realizado por Oliveira (1979) que verificou que, o coeficiente de correlação entre peso da fêmea e peso de sua postura possuiu um alto valor $(r=0,89)$, e por regressão linear esclareceu o grau de relacionamento existente entre esses parâmetros. Davey et al. (1980) encontraram uma correlação altamente significativa $(r>0,8)$ para o peso da fêmea e a massa de ovos, para ambos os grupos. Gloria et al. (1993) verificaram uma alta correlação entre peso da massa de ovos e peso da fêmea $(r=0,82)$. Barriga et al. (1995) relataram que há uma alta correlação entre peso ao desprendimento e peso dos ovos e que outras características foram independentes. Azevedo (1996) constatou uma forte correlação entre o peso médio da massa de ovos com o peso médio das teleóginas.

Nagar (1968) verificou que o peso da fêmea influencia o período de postura e, conseqüentemente, a postura diária e a postura total.

\section{CONSIDERAÇÕES FINAIS}

De forma clássica o estudo da resistência dos bovinos ao seu principal parasito tem sido aquela utilizada pelos australianos Wharton e Utech (1970), porém ela não evidencia de que forma sua resistência interfere na biologia de R. (B.) microplus.

Somando-se a essa condição há o fator de que a literatura não apresenta de forma equânime os parâmetros biológicos das fases parasitárias e não parasitárias das fêmeas, dos ovos, das larvas, das ninfas de $R$. (B.) microplus.

Vimos, assim, contribuir com esta compilação para facilitar os trabalhos de pesquisa e apontar os espaços deixados, permitindo sua complementação em estudos futuros. 


\section{REFERÊNCIAS}

ALMEIDA, A. T. S. Avaliação da resistência adquirida em quatro raças de bovinos à espécie Boophilus microplus (Canestrini, 1887) (Acari: Ixodidae) medida pelos parâmetros biológicos da fase de vida livre. Tese de Doutorado em Ciências Veterinárias, Instituto de Veterinária, UFRRJ, Seropédica, RJ, 2002.

ALVARADO, R.U. e GONZALES, J.C. A postura e a viabilidade do Boophilus microplus (Canestrini, 1887) (Acarina, Ixodidae) em condições de laboratório. Revista Latinoamericana de Microbiologia 21: 31 - 36, 1979.

ARAGÃO, H.B. Ixodidas brasileiros e de alguns paizes limitrophes. Memórias do Instituto Oswaldo Cruz 31: $759-843,1936$.

AZEVEDO, J.S.C. Características populacionais, nutricionais e reprodutivas do carrapato Boophilus microplus (CANESTRINI, 1887) afetadas pelo desenvolvimento de resistência imune em bovinos artificialmente infestados. Tese de Mestrado. UFRGS. 1996. 159p.

BARRIGA, O. O., SILVA, S. S. e AZEVEDO, J. S. C. Relationships and influences between Boophilus microplus characteristics in tick-naive or repeatedly infested cattle. Veterinary Parasitology 56: $225-238,1995$.

BENNETT, G. F. Oviposition of Boophilus microplus (Canestrini) (Acarida: Ixodidae) I. Influence of tick size on egg production. Acarologia 16(1): 52 - 61, 1974.

BENNETT, G. F. Oviposition of Boophilus microplus (Canestrini) (Acarida: Ixodidae) II. Influence of temperature, humidity and light. Acarologia 16 (2): 250 - 257, 1974.

BITTENCOURT, A. J. Boophilus microplus (Canestrini, 1887): infestações artificiais, biologia da fase não-parasitária e prevalência em caprinos e eqüinos. Tese de Mestrado. Itaguaí, RJ, UFRRJ. 1990. 88p.

CARVALHO, L. B.et al A. Evaluation in vitro of the infection times of engorged females of Rhipicephalus (Boophilus) microplus by the entomopathogenic nematode Steinernema glaseri CCA strain. Ciência Rural, Santa Maria, v.40, n.4, p.939-943, abr, 2010.

CHAGAS, A. C. S., FURLONG, J., NASCIMENTO. C. B. Comportamento e ecologia de fêmeas ingurgitadas do carrapato Boophilus microplus em pastagem de Brachiaria decumbens no Brasil. Brazilian Journal of Veterinarian Research and Animal Science, São Paulo, v. 38, n. 4, p. 188-191, 2001.

COSTA, A. L. Bioecologia de Boophilus microplus (Canestrini, 1887) (Acarina: Ixodidae) no estado do Rio de Janeiro: oviposição e sazonalidade - Considerações preliminares. Tese de Mestrado. Itaguaí, RJ. UFRRJ. 1982. 37p.

DAVEY, R. B. , GARZA, J. Jr., THOMPSON, G .D. and DRUMMOND, R. O. Ovipositional biology of the southern cattle tick, Boophilus microplus (Acari: Ixodidae), in the laboratory. Journal of Medical Entomological 17 (2): 117 - 121, 1980.

FURLONG, J. Comportamento de Boophilus microplus (Canestrini, 1887) e Amblyomma cajennense (Fabricius, 1787) em infestações consecutivas ou simultâneas em bovinos: análise preliminar de parâmetros biológicos. Tese de Doutorado. Rio de Janeiro, UFRRJ, 1990. 92p. 
GLORIA, M.A., DAEMON, E., FACCINI, J. L. H. e GRISI, L. Influência de diferentes temperaturas sobre a biologia da fase não parasitária de Boophilus microplus (Can., 1887) (Acari: Ixodidae). Revista Brasileira de Parasitologia Veterinária 2(2): 85 - 91, 1993.

HITCHCOCK, L. F. Studies of the non-parasitic stages on the cattle tick, Boophilus microp/us (Canestrini) (Acarina: Ixodidae). Australian Journal of Zoology 3: 295-311, 1955.

HONER, M. R. e GOMES, A. O manejo integrado de mosca dos chifres, berne e carrapato em gado de corte. Campo Grande EMBRAPA - CNPGC, Circular Técnica no. 22, 1990. 60p.

HORN, S. C. e ARTECHE, C. C. P. Situação parasitária da pecuária no Brasil. A Hora Veterinária, 4 (23) : 12-32, 1985.

HOOGSTRAAL, H. Review article: The epidemiology of tick-borne Crimean-Congo Hemorrhagic Fever in Asia, Europe and Africa. Jour. Med. Entomol., 15 (4): 307-417, 1979. Apud EVANS, D.E. Ecologia e o carrapato Boophilus microplus. In: Seminário Nacional sobre Parasitoses dos Bovinos, 1, Campo Grande, MS, 1979. Anais. Campo Grande, p. 217-229, 1979.

KAUFMAN, W. R. Tick-host interaction: a synthesis of current concepts. Parasitology Today 5 (2): $47-56,1989$.

KHAN, M. H. Biology of Boophilus microplus (Can.) in Adamans. Indian Journal of Animal Health $25(1): 7-9,1986$.

LOMBARDO, R. A. Socioeconomic importance of the tick problems in the Americas. Panel on the importance of tick control in the development of programs for animal health in the Americas. Prov. Agenda. Item $9: 18 \mathrm{pp}$. FAO-WHO VII. Interamerican Meeting at the Ministerial level on foot-and-mouth and zoonosis control. Guatemala, 16-19 April, 1975. Apud EVANS, D.E. Ecologia e o carrapato Boophilus microplus. In: Seminário Nacional Sobre Parasitoses dos Bovinos, 1, Campo Grande, MS, 1979. Anais, Campo Grande, p. 217-229, 1979.

LOUZADA, G. L., DAEMON, E. Efeito da imersão de fêmeas ingurgitadas de Boophilus microplus (Canestrini, 1887) (Acari: Ixodidae) em água destilada sobre os parâmetros biológicos ligados a oviposição. Revista Brasileira de Parasitologia Veterinária, 12, 3, 115-120, 2003.

MARADEY, J. A. O. Efeitos das raças Santa Gertrudis e Aberdeen Angus em infestações de Boophilus microplus (Can., 1887) Tese de Mestrado. Porto Alegre, UFRGS. 1983. 70p.

MURRELL A., BARKER S. C. Synonymy of Boophilus Curtice, 1891 with Rhipicephalus Koch, 1844 (Acari: Ixodidae). Systematic Parasitology. 56:169-172, 2003.

NAGAR, S. K. On the significance of the duration of preoviposition and oviposition periods in ixodid ticks. Acarologia 10: 621 - 629, 1968

OLIVEIRA, G. P. Relação entre o peso da postura e o peso da fêmea ingurgitada de Boophilus microplus (Can.) (Acarina: Ixodidae) Científica 7 (2): 273 - 276, 1979.

RHOR, C. J. Estudos sobre Ixodidas do Brasil. Tese, Instituto Oswaldo Cruz. Gomes \& Irmão, Rio de Janeiro, RJ, 1909. 220 p.

SANTOS, A. P., FURLONG, J. Competição intraespecífica em Boophilus microplus. Ciência Rural, Santa Maria, v.32, n.6, p.1033-1038, 2002. 
SARTOR, I. F., FACCINI, J. L. H., KUCHEMBUCK, M. R. G. e CURI, P. R. Estudo comparativo da resistência ao carrapato Boophilus microplus (Canestrini) (Acari) em bovinos das raças Gir, Holandesa e mestiços 1⁄2 Gir-Holandês. Veterinária e Zootecnia 4: 25 - 33, 1992.

SHORT, N. J., FLOYD, R. B., NORVAL, R. A. I., SUTHERST, R. W. Development rates, fecundity and survival of developmental stages of the ticks Boophilus appendiculatus, Boophilus decoloratus and Boophilus microplus under field condition in Zimbabwe. Experimental \& Applied of Acarology 6: 123-141, 1989.

SILVA, W. W., et al. Efeitos do neem (Azadirachta indica A. Juss) e do capim santo [Cymbopogon citratus (DC) Stapf] sobre os parâmetros reprodutivos de fêmeas ingurgitadas de Boophilus microplus e Rhipicephalus sanguineus (Acari: Ixodidae) no semiárido paraibano. Revista Brasileira de PIantas Medicinal, Botucatu, v.9, n.3, p. 1-5, 2007.

SUTHERST, R. W., WHARTON, R. H. e UTECH, K. R. B. W. Guide to studies on tick ecology. CSIRO Australian Division of Entomology Technical Paper 14: 1 - 59, 1978.

VASCONCELOS, O. T., et al. Ecologia de carrapatos XVIII - comparação de números, pesos e capacidades de oviposição entre teleóginas desprendidas diariamente de bezerros taurino e zebuíno naturalmente infestados por Boophilus microplus. Ars Veterinária 2 (2): 237-246, 1986.

VALLE, M. R. Respuesta inmunológica contra garrapatas. Biotecnología Aplicada 17: 215 $220,2000$.

WAGLAND, R. B. M. Host resistance to cattle tick (Boophilus microplus) in Brahman (Bos indicus) cattle. I responses of previously unexposed cattle to four infestations with 20,000 larvae. Australian Journal Agricultural Research 26: 1073 - 1080, 1975.

WHARTON, R. H. e UTECH, K. B. W. The relation between engorgement and dropping of Boophilus microplus (Canestrini) (Ixodidae) to the assessment of tick numbers on cattle. Journal Australian Entomological Society, 9: 171 - 182, 1970.

WHARTON, R. H., UTECH, K. B. W. and SUTHERST, R. W. Tick resistant cattle for the control of Boophilus microplus. Proceedings of the $\mathbf{3}^{\text {rd }}$ International Congress of Acarology, 697 700, 1971. 